\title{
OPEN The effect of composition, microfluidization and process parameters on formation of oleogels for ice cream applications
}

\author{
E. Silva-Avellaneda, K. Bauer-Estrada, R. E. Prieto-Correa \& M. X. Quintanilla-Carvajal
}

The use of oleogels is an innovative and economical option for the technological development of some food products, among them ice creams. The aim of this study was to establish the best processing conditions to obtain an emulsion which form oleogels with the lowest $\zeta$-potential and average droplet size (ADS) for use as ice cream base. Using surface response methodology (SRM), the effects of three numerical factors (microfluidization pressure, oil and whey protein concentration, WP) and four categorical factors (oil type, temperature, surfactant, and type of WP) on formation of emulsions were assessed. The response variables were $\zeta$, ADS, polydispersity index (PDI), viscosity ( $\eta$ ), hardness, cohesiveness and springiness. Additionally, a numerical optimization was performed. Two ice creams containing milk cream and oleogel, respectively were compared under the optimization conditions. Results suggest oleogels obtained from the microfluidization of whey and high oleic palm oil are viable for the replacement of cream in the production of ice cream.

Among several fat-rich products, ice creams represent a very attractive product, consumed worldwide by all ages. However, the composition of the cream used to prepare ice creams is mainly saturated fats, called also solid fats, and its mainly purpose is to confer structure to the product ${ }^{1}$. Currently, consumers are increasingly aware of their dietary sources of fat, and vegetable oils such as coconut, soy and high oleic palm oil can be used as an alternative to solid fats by producing oil emulsions in water with a healthier fatty acid profile ${ }^{2}$. Iordache and Jelen ${ }^{3}$ concluded that microfluidized solutions of heated WPs resulted in the production of non-sedimented opaque suspensions, probably by the disintegration of insoluble aggregates into particles of substantially reduced size; when oil is added to these solutions and non-sedimented suspensions are formed, they can be called oleogels. These oleogels are defined as a high technological product produced by oil structuring food-approved polymers, that can be used to replace solid fat content and create optimal fat structure in ice creams ${ }^{4,5}$.

Whey protein (WP) has been recognized as a high value byproduct, and possess several advantages related to protein functionalities and the ability to form oleogels ${ }^{6}$. Proteins like $\beta$-lactoglobulin $(\sim 18.36 \mathrm{kDa})$ and a-lactalbumin $(\sim 14.17 \mathrm{kDa})$, present in the WP, display different functionalities such as emulsification and gelling according to the physicochemical treatment ( $\mathrm{pH}$, pressure, temperature) to which they are subjected ${ }^{7}$. The functionality of WP is closely related to the composition and amino acid sequence of these proteins, which allows a specific role or function in a food to be fulfilled, such as providing nutritional value or increasing solubility, gelation or emulsification in different matrices ${ }^{8}$.

One of the most widely used technologies for the production of emulsions is microfluidization (MF), which is a high energy method that uses high pressure to force a fluid through microchannels, thereby emulsifying it with the combined effects of cavitation, shear and impact ${ }^{9}$. In this work, microfluidization was chosen to emulsify WP with oils mentioned above and obtain oleogels, since it is a fully scalable process and has been implemented in different industries (food, pharmaceutical, cosmetic) for its high efficiency to decrease the particle size of different matrices ${ }^{9,10}$. Different studies suggest that MF affects the structure of the native protein and can produce significant differences when compared to denaturation and heat-induced aggregation, as MF can break intermolecular bonds, leading to protein fragmentation ${ }^{11}$. However, MF can greatly increase the hydrophobic nature of 
the surface of an absorbed protein layer by transforming aggregates of WPs into smaller aggregates, as has been demonstrated in emulsions. MF transforms these aggregates into smaller particles, leading to enhanced interdroplet interactions and thereby increasing their potential application as emulsions in the preparation of gels ${ }^{12}$.

In recent years, oleogels have been of interest due to of their potential applications in food (as fat replacements), pharmaceuticals (as drug delivery systems) and cosmetics ${ }^{13}$. Solvent exchange routes ${ }^{14}$, temperature increases and solvent exchange ${ }^{6}$, and stirring at low temperature ${ }^{13}$ have been used to form oleogels, but the effects of MF on obtaining oleogels with different types of oils has not been studied. Finally, the ability to create and stabilize a dispersed food system depends mainly on its structural properties, extrinsic factors and process of creation. Therefore, the objective of this study was to evaluate through surface response methodology (SRM) the effect of various relevant industrial process parameters, such as temperature, pressure, concentration of surfactant, different oils and WP type, on the production of oleogels. These oleogels can be used as possible bases to produce ice cream and to thereby enhance their use through rheology and texture analysis.

\section{Materials and methods}

Materials. Three types of WP were collected from different regions of Colombia, WP1 supplied by Lácteos Castilac Ltda, WP2 supplied by Lactolife S.A.S from Cundinamarca, and WP3 supplied by Lácteos del campo Caqueteño S.A.S from Caquetá. Different oils were used for the preparation of emulsions: high oleic palm oil, HOPO (Fedepalma, Bogotá, Colombia); coconut oil, VCO (A of coconut, Colombia) and soy oil, SO (Carulla, Colombia). VCO and SO were acquired from a local market in Chia, Colombia.

Spray drying. The collected whey was dried in a pilot scale spray dryer (GEA Process Engineering, Mobile Minor, GEA Niro, Denmark). During this process, an air inlet temperature of $215^{\circ} \mathrm{C}$ and an air outlet temperature of $100^{\circ} \mathrm{C}$ were controlled along with the whey inlet flow and the atomized air pressure $(0.8-1 \text { bar })^{15}$. A two-stream continuous-flow pneumatic nozzle ( $1 \mathrm{~mm}$ in diameter) with a capacity of $5 \mathrm{~L} \mathrm{~h}^{-1}$ was used as the atomizer system.

Experimental design. To evaluate the emulsification and gelation functionality of WP, a type IV-optimal response surface design was used (Table 1) in the Design Expert Software V8.0.7.1 (Stat-Ease Inc., Minneapolis, MN, USA). Three numerical factors were evaluated at three levels: pressure (A) (65-130 MPa), oil concentration (B) $(6-10 \%(w / w))$, and WP concentration (C) $(30-50 \%(w / w))$; four categorical factors were evaluated: type of oil (D) (VCO, HOPO and SO)), temperature (E) (with and without $\mathrm{T}^{\circ}$ control), surfactant (F) (with and without surfactant) and type of WP (G) (WP1, WP2 and WP3).

The response variables were $\zeta(\mathrm{mV})$, ADS $(\mathrm{nm})$, PDI, and $\eta_{\text {Fresh }}(\mathrm{mPa} \mathrm{s}), \eta_{\text {Stored } 20^{\circ} \mathrm{C}}(\mathrm{mPa} \mathrm{s}), \eta_{\text {Stored } 4{ }^{\circ} \mathrm{C}}(\mathrm{mPa}$ $\mathrm{s})$, hardness $(\mathrm{N})$, cohesiveness $(\mathrm{N} \mathrm{mm})$ and springiness $(\mathrm{mm})$. A statistical significance test was used in the total error criteria with a confidence level of $95 \%$. Significant factors in the model were identified through analysis of variance (ANOVA) with a confidence level of $95 \%$. Model fit was evaluated with the $\mathrm{R}^{2}$ value and the adjusted $\mathrm{R}^{2}$ value. The graphic and numerical optimization of the Design Expert software was used for response optimization. One optimization system was formulated for an emulsion with the lowest $\zeta$ and ADS for use as an ice cream base.

Preparation of the emulsions. In accordance with the experimental design (Table 1), oil with or without surfactant (soy lecithin) was slowly added to the WP solution at a concentration of $1 \%(\mathrm{w} / \mathrm{w})$ with respect to the oil; the samples were homogenized in an Ultra-Turrax (T-25 basic, IKA, Staufen, Germany) homogenizer with a S25 KV-25G geometry at $15,000 \mathrm{rpm}$ for $10 \mathrm{~min}$. A volume of $180 \mathrm{~mL}$ of each run was microfluidized at the pressure indicated in the experimental design (65-130 MPa) for 3 cycles with temperature controlled at $5{ }^{\circ} \mathrm{C}$ or uncontrolled in a Microfluidizer (Microfluidics, Newton, USA) ${ }^{3}$. Uncontrolled temperatures ranges between 5 and $42{ }^{\circ} \mathrm{C}$. Approximately $40 \mathrm{~mL}$ of each fresh emulsion were placed in $50-\mathrm{mL}$ Falcon tubes and stored during 3 days at room temperature $\left(20^{\circ} \mathrm{C}\right)$ and in a refrigerator $\left(4^{\circ} \mathrm{C}\right)$ for further analysis.

ADS, PDI and $\xi$. The ADS and PDI of the fresh emulsions were obtained by dynamic light scattering (DLS) dispersion using a disposable cell (DTS0012). The net electric charge of the WPC solutions was determined by measuring the $\xi$ using a foldable capillary cell (DTS1070). Measurements were performed on a Zetasizer Nano ZS (Malvern Instruments, Malvern, UK). For the measurements, 1: 1000 dispersions were prepared in accordance with the methodology of Qian et al. ${ }^{16}$, and the samples were equilibrated in the equipment at $25^{\circ} \mathrm{C}$. Each measurement was performed in triplicate with a scattering angle of $173^{\circ}$.

Determination of viscosity. The viscosity of fresh emulsions and those stored at $20^{\circ} \mathrm{C}$ and $4{ }^{\circ} \mathrm{C}$ was measured on a rheometer (Para-Physica MCR 502, Anton Paar GmbH, Ostfildern, Germany), and a profiled plate geometry (PP50) with a gap of $0.5 \mathrm{~mm}$ and a speed between 1 and $100 \mathrm{~s}^{-1}$ was performed. Measurements were carried out at room temperature. The viscosity was reported at a shear rate of $25 \mathrm{~s}^{-1}$.

Preparation of oleogels. Approximately $15 \mathrm{~g}$ of fresh emulsions obtained from each run were placed in stainless steel molds to heat-cure in a water bath at $90{ }^{\circ} \mathrm{C}$ for $90 \mathrm{~min}$ and then placed in an ice bath for $30 \mathrm{~min}$ in order to obtain the oleogels ${ }^{17}$.

Analysis of texture parameters. The WP oleogels resulting from each run were compressed axially in two consecutive cycles at a test speed of $2 \mathrm{mms}^{-1}$, with a flat geometry $25 \mathrm{~mm}$ in diameter. Measurements were performed in triplicate. A texture profile analysis (TPA) was carried out to determine the hardness, cohesive- 


\begin{tabular}{|c|c|c|c|c|c|c|c|c|c|c|c|c|c|c|c|c|}
\hline \multirow[b]{2}{*}{ Run } & \multicolumn{3}{|c|}{ Numeric factors } & \multicolumn{4}{|c|}{ Categoric factors } & \multicolumn{9}{|c|}{ Response variables } \\
\hline & \begin{tabular}{|l|} 
A: \\
Pressure \\
(MPa)
\end{tabular} & $\begin{array}{l}\text { B: Oil } \\
\text { (\%) }\end{array}$ & $\begin{array}{l}\text { C: } \\
\text { Whey } \\
\text { (\%) }\end{array}$ & D: Oil & \begin{tabular}{|l|}
$\mathrm{E}:$ \\
Control \\
$\mathrm{T}^{\circ}$
\end{tabular} & $\begin{array}{l}\text { F: } \\
\text { Lecithin }\end{array}$ & G: WP & $\zeta(\mathrm{mV})$ & $\begin{array}{l}\text { ADS } \\
(\mathbf{n m})\end{array}$ & PDI & $\begin{array}{l}\eta_{\text {Fresh }} \\
(\mathbf{m P a} \\
\mathbf{s})\end{array}$ & $\begin{array}{l}\eta_{\text {Stored } 20^{\circ} \mathrm{C}} \\
\text { (mPa s) }\end{array}$ & $\begin{array}{l}\eta_{\text {Stored } 4{ }^{\circ} \mathrm{C}} \\
\text { (mPa s) }\end{array}$ & $\begin{array}{l}\text { Hardness } \\
(\mathrm{N})\end{array}$ & Cohesiveness & Springiness \\
\hline 1 & 130.0 & 6.0 & 50.0 & HOPO & No & Yes & WP2 & -22.8 & 377.5 & 0.47 & 315.6 & 573.6 & 721.4 & 147.3 & 1.51 & 0.44 \\
\hline 2 & 65.0 & 6.0 & 33.1 & SO & No & Yes & WP3 & -28.3 & 298.8 & 0.26 & 24.0 & 665.6 & 80.0 & 32.3 & 1.59 & 0.28 \\
\hline 3 & 130.0 & 6.1 & 44.3 & VCO & No & No & WP2 & -21.1 & 271.3 & 0.25 & 21.6 & 159.4 & 146.5 & 220.7 & 2.07 & 0.60 \\
\hline 4 & 76.7 & 9.0 & 50.0 & SO & No & Yes & WP1 & -29.3 & 274.6 & 0.26 & 188.7 & 655.8 & 427.5 & 61.0 & 1.40 & 0.03 \\
\hline 5 & 89.6 & 7.1 & 31.3 & SO & Yes & No & WP3 & -28.5 & 320.0 & 0.27 & 24.1 & 89.8 & 213.6 & 87.5 & 1.62 & 0.44 \\
\hline 6 & 130.0 & \begin{tabular}{|l|}
8.7 \\
\end{tabular} & 50.0 & SO & Yes & No & WP1 & -26.7 & 290.6 & \begin{tabular}{|l|}
0.39 \\
\end{tabular} & 581.4 & $\mid 2489.3$ & 1547.4 & \begin{tabular}{|l|}
168.7 \\
\end{tabular} & 1.43 & 0.44 \\
\hline 7 & 65.0 & 8.5 & 50.0 & VCO & No & No & WP2 & -17.7 & 237.8 & \begin{tabular}{|l|}
0.19 \\
\end{tabular} & 47.4 & 318.5 & 210.0 & 242.8 & 1.95 & 0.54 \\
\hline 8 & 120.3 & 6.0 & 30.0 & VCO & Yes & No & WP1 & -26.7 & 252.8 & 0.23 & 35.8 & 864.1 & 292.2 & 46.8 & 1.90 & 0.12 \\
\hline 9 & 65.0 & 10.0 & 30.0 & HOPO & Yes & No & WP1 & -29.4 & 552.3 & 0.50 & 57.1 & 1676.8 & 553.6 & 40.7 & 1.52 & \begin{tabular}{|l|}
0.01 \\
\end{tabular} \\
\hline 10 & \begin{tabular}{|l|}
65.0 \\
\end{tabular} & 9.9 & 39.2 & SO & Yes & Yes & WP1 & -29.3 & 500.5 & 0.42 & 96.3 & 812.8 & 471.6 & 47.0 & 1.50 & $\begin{array}{l}0.10 \\
\end{array}$ \\
\hline 11 & \begin{tabular}{|l|}
94.3 \\
\end{tabular} & 9.6 & 36.0 & HOPO & No & Yes & WP3 & -28.7 & 344.2 & 0.32 & 45.8 & 397.0 & 341.1 & 116.2 & 1.62 & 0.32 \\
\hline 12 & 124.2 & 7.0 & 39.0 & VCO & No & Yes & WP3 & -26.4 & 217.3 & 0.16 & 53.8 & 358.7 & 97.9 & 75.8 & 1.47 & \begin{tabular}{|l|}
0.48 \\
\end{tabular} \\
\hline 13 & 130.0 & 6.0 & 30.0 & HOPO & Yes & No & WP3 & -26.8 & 221.7 & 0.14 & 34.3 & 3416.3 & 345.2 & 63.7 & 1.52 & \begin{tabular}{|l|}
0.61 \\
\end{tabular} \\
\hline 14 & \begin{tabular}{|l|}
104.0 \\
\end{tabular} & 6.0 & 30.0 & SO & No & No & WP1 & -29.5 & 246.0 & 0.22 & 46.0 & 710.7 & 250.7 & \begin{tabular}{|l|}
110.9 \\
\end{tabular} & 2.05 & 0.21 \\
\hline 15 & 65.0 & \begin{tabular}{|l|}
8.8 \\
\end{tabular} & \begin{tabular}{|l|}
34.9 \\
\end{tabular} & HOPO & Yes & Yes & WP2 & -19.6 & 379.0 & 0.30 & 6.1 & 50.3 & 7.16 & 51.4 & \begin{tabular}{|l|}
1.49 \\
\end{tabular} & 0.01 \\
\hline 16 & \begin{tabular}{|l|}
65.0 \\
\end{tabular} & 10.0 & 47.4 & SO & Yes & \begin{tabular}{|l|} 
No \\
\end{tabular} & WP3 & -27.3 & 347.9 & \begin{tabular}{|l|}
0.26 \\
\end{tabular} & 376.2 & \begin{tabular}{|l|}
1334.0 \\
\end{tabular} & 1888.3 & 123.3 & 1.54 & \begin{tabular}{|l|} 
\\
\end{tabular} \\
\hline 17 & 130.0 & 9.7 & 30.0 & SO & No & Yes & WP3 & -28.3 & 338.9 & 0.32 & 36.7 & 494.1 & 211.2 & 39.4 & 1.43 & \begin{tabular}{|l|}
0.06 \\
\end{tabular} \\
\hline 18 & \begin{tabular}{|l|}
114.9 \\
\end{tabular} & 7.1 & 32.1 & SO & Yes & Yes & WP1 & -28.3 & \begin{tabular}{|l|}
395.8 \\
\end{tabular} & 0.38 & 30.1 & 845.9 & 417.0 & 34.2 & 1.75 & \begin{tabular}{|l|l|}
0.02 \\
\end{tabular} \\
\hline 19 & 125.0 & 7.3 & 30.0 & HOPO & Yes & No & WP2 & -27.2 & 215.3 & 0.12 & 6.3 & 9.2 & 10.5 & \begin{tabular}{|l|}
116.8 \\
\end{tabular} & 1.54 & \begin{tabular}{|l|}
0.51 \\
\end{tabular} \\
\hline 20 & \begin{tabular}{|l|}
87.4 \\
\end{tabular} & 6.0 & 50.0 & HOPO & No & Yes & WP1 & -29.6 & 210.6 & 0.19 & 267.5 & \begin{tabular}{|l|}
1910.9 \\
\end{tabular} & 922.9 & 88.0 & 1.32 & 0.16 \\
\hline 21 & 128.6 & 7.4 & 42.0 & SO & No & Yes & WP2 & -22.8 & 821.8 & 0.51 & 24.4 & 291.5 & 120.5 & 238.6 & 1.57 & 0.42 \\
\hline 22 & 67.0 & 6.0 & 30.0 & HOPO & No & Yes & WP1 & -28.7 & 291.7 & 0.23 & 47.1 & 5977.8 & 886.5 & 18.1 & 1.48 & 0.31 \\
\hline 23 & \begin{tabular}{|l|}
104.0 \\
\end{tabular} & 10.0 & 37.0 & SO & Yes & Yes & WP2 & -19.8 & 521.0 & 0.48 & 6.7 & 13.1 & 7.90 & 103.5 & 1.66 & \begin{tabular}{|l|l|}
0.04 \\
\end{tabular} \\
\hline 24 & 81.9 & 6.0 & 41.0 & VCO & No & Yes & WP2 & -17.3 & \begin{tabular}{|l|l|}
422.7 \\
\end{tabular} & 0.44 & 9.3 & 15.5 & 9.90 & 76.4 & 1.77 & 0.11 \\
\hline 25 & \begin{tabular}{|l|}
130.0 \\
\end{tabular} & 8.0 & 30.4 & HOPO & No & No & WP1 & -30.0 & 379.3 & 0.44 & 46.6 & 937.5 & 755.6 & 114.2 & 1.43 & 0.44 \\
\hline 26 & 89.6 & 7.1 & 31.3 & SO & Yes & No & WP3 & -27.5 & 283.7 & \begin{tabular}{|l|}
0.25 \\
\end{tabular} & 77.4 & 81.8 & 346.2 & 83.1 & 1.43 & \begin{tabular}{|l|}
0.60 \\
\end{tabular} \\
\hline 27 & 94.3 & 9.6 & 36.0 & HOPO & No & Yes & WP3 & -29.2 & 319.7 & 0.26 & 52.0 & $\begin{array}{l}551.8 \\
\end{array}$ & 242.6 & 77.9 & 1.63 & \begin{tabular}{|l|l|}
0.19 \\
\end{tabular} \\
\hline 28 & 98.2 & 7.2 & 37.5 & HOPO & No & No & WP3 & -27.9 & 236.1 & 0.15 & 90.0 & 1483.8 & 570.1 & 102.5 & 1.45 & \begin{tabular}{|l|}
0.81 \\
\end{tabular} \\
\hline 29 & 123.5 & 6.0 & \begin{tabular}{|l|l|}
48.9 \\
\end{tabular} & SO & Yes & Yes & WP3 & -28.5 & \begin{tabular}{|l|}
193.2 \\
\end{tabular} & 0.12 & 92.4 & 716.4 & 202.9 & 115.0 & 1.40 & 0.76 \\
\hline 30 & 130.0 & 10.0 & 30.0 & VCO & No & Yes & WP2 & -20.2 & \begin{tabular}{|l|}
787.8 \\
\end{tabular} & \begin{tabular}{|l|}
0.46 \\
\end{tabular} & 5.7 & 23.9 & 6.7 & 71.9 & 1.67 & \begin{tabular}{|l|}
0.09 \\
\end{tabular} \\
\hline 31 & 101.4 & 10.0 & 50.0 & VCO & No & No & WP1 & -29.3 & 310.2 & 0.36 & 603.0 & 4730.6 & 2401.6 & 51.1 & 1.63 & 0.32 \\
\hline 32 & 83.6 & 9.5 & 31.5 & VCO & No & Yes & WP1 & -27.7 & 431.0 & 0.46 & 97.9 & 774.2 & 315.9 & 57.1 & 1.52 & \begin{tabular}{|l|l|}
0.11 \\
\end{tabular} \\
\hline 33 & \begin{tabular}{|l|}
130.0 \\
\end{tabular} & 7.7 & 49.3 & VCO & Yes & Yes & WP2 & -16.4 & 700.3 & 0.52 & 269.7 & 1451.7 & 1852.3 & 225.9 & 1.60 & 0.30 \\
\hline 34 & 71.5 & 7.4 & 50.0 & HOPO & Yes & Yes & WP3 & -27.5 & 279.1 & 0.29 & 94.5 & 1310.3 & 1171.1 & \begin{tabular}{|l|}
116.1 \\
\end{tabular} & 1.47 & \begin{tabular}{|l|l|}
0.74 \\
\end{tabular} \\
\hline 35 & 124.2 & 7.0 & 39.0 & VCO & No & Yes & WP3 & -27.2 & 228.5 & 0.16 & 94.5 & 883.2 & 188.1 & \begin{tabular}{|l|}
78.1 \\
\end{tabular} & \begin{tabular}{|l|}
1.48 \\
\end{tabular} & \begin{tabular}{|l|}
0.42 \\
\end{tabular} \\
\hline 36 & 65.0 & 10.0 & 50.0 & HOPO & No & No & WP1 & -30.5 & 296.6 & 0.22 & 562.3 & 2295.6 & 1622.9 & 57.8 & 2.15 & 0.46 \\
\hline 37 & \begin{tabular}{|l|}
65.7 \\
\end{tabular} & 7.8 & 477.7 & VCO & Yes & Yes & WP1 & -28.7 & 535.3 & 0.51 & 221.0 & 571.8 & 527.5 & 56.4 & 1.40 & \begin{tabular}{|l|}
0.08 \\
\end{tabular} \\
\hline 38 & 94.3 & 10.0 & 50.0 & HOPO & No & No & WP2 & -22.0 & 228.6 & 0.14 & \begin{tabular}{|l|}
108.6 \\
\end{tabular} & 323.7 & 187.7 & 280.5 & 1.51 & 0.33 \\
\hline 39 & 72.1 & 9.2 & \begin{tabular}{|l|}
36.4 \\
\end{tabular} & VCO & Yes & No & WP2 & -21.8 & \begin{tabular}{|l|}
320.1 \\
\end{tabular} & 0.24 & 8.1 & 16.5 & 8.84 & 78.3 & \begin{tabular}{|l|}
1.58 \\
\end{tabular} & \begin{tabular}{|l|l|}
0.18 \\
\end{tabular} \\
\hline 40 & \begin{tabular}{|l|}
100.8 \\
\end{tabular} & 6.3 & 42.6 & HOPO & Yes & No & WP1 & -28.2 & 203.5 & 0.14 & 184.2 & 912.8 & 669.9 & 88.3 & 1.47 & \begin{tabular}{|l|}
0.58 \\
\end{tabular} \\
\hline 41 & 114.6 & 7.9 & 40.4 & VCO & No & No & WP1 & -28.4 & \begin{tabular}{|l|}
304.8 \\
\end{tabular} & 0.28 & 201.3 & 961.9 & 328.4 & 179.5 & 1.44 & \begin{tabular}{|l|}
0.38 \\
\end{tabular} \\
\hline 42 & 130.0 & 10.0 & \begin{tabular}{|l|}
45.9 \\
\end{tabular} & HOPO & Yes & Yes & WP1 & -28.4 & 299.1 & \begin{tabular}{|l|}
0.27 \\
\end{tabular} & 167.3 & 705.7 & 362.2 & 75.3 & 1.40 & $\begin{array}{l}0.10 \\
\end{array}$ \\
\hline 43 & 100.8 & 6.3 & 42.6 & HOPO & Yes & No & WP1 & -28.5 & 241.9 & 0.22 & 133.0 & 670.9 & 317.4 & 66.8 & 1.42 & 0.56 \\
\hline 44 & \begin{tabular}{|l|}
114.9 \\
\end{tabular} & \begin{tabular}{|l|}
7.1 \\
\end{tabular} & 32.1 & SO & Yes & Yes & WP1 & -27.8 & 283.3 & \begin{tabular}{|l|}
0.24 \\
\end{tabular} & 45.3 & 748.6 & 196.4 & 39.9 & \begin{tabular}{|l|}
1.82 \\
\end{tabular} & \begin{tabular}{|l|}
0.04 \\
\end{tabular} \\
\hline 45 & 65.0 & 6.8 & \begin{tabular}{|l|}
41.9 \\
\end{tabular} & VCO & No & No & WP1 & -29.2 & 282.0 & 0.25 & 188.3 & 1021.7 & 374.6 & \begin{tabular}{|l|}
111.9 \\
\end{tabular} & 1.41 & \begin{tabular}{|l|l|}
0.49 \\
\end{tabular} \\
\hline 46 & 130.0 & 6.0 & 50.0 & VCO & No & Yes & WP1 & -23.8 & 172.3 & 0.18 & 299.9 & 2452.8 & 1837.5 & 73.9 & 1.51 & 0.03 \\
\hline 47 & 130.0 & 10.0 & 40.0 & SO & No & No & WP1 & -30.5 & 346.3 & 0.42 & 208.2 & 1021.8 & 542.8 & 122.1 & 1.21 & \begin{tabular}{|l|l|}
0.37 \\
\end{tabular} \\
\hline 48 & 65.0 & 6.0 & 34.9 & HOPO & No & No & WP2 & -24.9 & 236.8 & 0.16 & 6.00 & 6.55 & 6.39 & 60.8 & 1.55 & 0.06 \\
\hline 49 & \begin{tabular}{|l|}
130.0 \\
\end{tabular} & 10.0 & 50.0 & HOPO & No & No & WP3 & -27.7 & 226.6 & 0.18 & \begin{tabular}{|l|}
410.3 \\
\end{tabular} & 3177.7 & 634.2 & \begin{tabular}{|l|}
163.6 \\
\end{tabular} & 1.73 & \begin{tabular}{|l|}
0.57 \\
\end{tabular} \\
\hline 50 & \begin{tabular}{|l|}
89.7 \\
\end{tabular} & 6.7 & 50.0 & SO & No & No & WP3 & -26.5 & 212.8 & 0.15 & 347.4 & \begin{tabular}{|l|}
1479.4 \\
\end{tabular} & 2385.5 & 159.3 & 1.79 & \begin{tabular}{|l|}
0.69 \\
\end{tabular} \\
\hline 51 & 65.0 & 9.2 & 30.7 & SO & No & No & WP2 & -28.1 & 295.3 & 0.15 & 5.80 & 7.90 & 6.21 & 93.1 & 1.61 & 0.46 \\
\hline 52 & \begin{tabular}{|l|}
80.9 \\
\end{tabular} & 6.0 & 50.0 & VCO & Yes & No & WP3 & -27.8 & 225.4 & 0.19 & \begin{tabular}{|l|}
110.1 \\
\end{tabular} & 2449.6 & 790.7 & 155.0 & 1.54 & \begin{tabular}{|l|}
0.60 \\
\end{tabular} \\
\hline 53 & \begin{tabular}{|l|}
130.0 \\
\end{tabular} & 9.8 & 38.0 & VCO & Yes & No & WP3 & -26.7 & 348.5 & \begin{tabular}{|l|}
0.37 \\
\end{tabular} & 120.2 & 551.1 & 278.1 & 161.4 & 1.64 & \begin{tabular}{|l|}
0.28 \\
\end{tabular} \\
\hline 54 & \begin{tabular}{|l|}
65.0 \\
\end{tabular} & 10.0 & 50.0 & VCO & No & Yes & WP3 & -28.3 & 288.6 & 0.34 & \begin{tabular}{|l|}
152.8 \\
\end{tabular} & \begin{tabular}{|l|}
1339.0 \\
\end{tabular} & 390.0 & 80.7 & 1.45 & 0.71 \\
\hline
\end{tabular}




\begin{tabular}{|c|c|c|c|c|c|c|c|c|c|c|c|c|c|c|c|c|}
\hline \multirow[b]{2}{*}{ Run } & \multicolumn{3}{|c|}{ Numeric factors } & \multicolumn{4}{|c|}{ Categoric factors } & \multicolumn{9}{|c|}{ Response variables } \\
\hline & $\begin{array}{l}\text { A: } \\
\text { Pressure } \\
\text { (MPa) }\end{array}$ & $\begin{array}{l}\text { B: Oil } \\
(\%)\end{array}$ & $\begin{array}{l}\text { C: } \\
\text { Whey } \\
(\%)\end{array}$ & D: Oil & \begin{tabular}{|l|} 
E: \\
Control \\
$\mathbf{T}^{\circ}$ \\
\end{tabular} & $\begin{array}{l}\text { F: } \\
\text { Lecithin }\end{array}$ & G: WP & $\zeta(\mathrm{mV})$ & $\begin{array}{l}\text { ADS } \\
(\mathbf{n m})\end{array}$ & PDI & $\begin{array}{l}\eta_{\text {Fresh }} \\
(\mathbf{m P a} \\
\text { s) }\end{array}$ & $\begin{array}{l}\eta_{\text {Stored } 20^{\circ} \mathrm{C}} \\
(\mathrm{mPa} \mathrm{s})\end{array}$ & $\begin{array}{l}\eta_{\text {Stored } 4{ }^{\circ} \mathrm{C}} \\
(\mathrm{mPa} \mathrm{s})\end{array}$ & $\begin{array}{l}\text { Hardness } \\
(\mathrm{N})\end{array}$ & Cohesiveness & Springiness \\
\hline 55 & 65.0 & 6.0 & 49.0 & SO & Yes & No & WP2 & -18.8 & 364.8 & 0.35 & 53.9 & 369.5 & 216.9 & 237.6 & 1.91 & 0.53 \\
\hline 56 & 81.3 & 8.6 & 30.0 & $\mathrm{VCO}$ & Yes & Yes & WP3 & -27.7 & 362.1 & 0.34 & 47.7 & 554.6 & 188.1 & 99.7 & 1.88 & 0.26 \\
\hline 57 & \begin{tabular}{|l|}
81.3 \\
\end{tabular} & 9.6 & 30.0 & $\mathrm{VCO}$ & No & No & WP3 & -25.7 & 393.6 & 0.41 & \begin{tabular}{|l|}
157.3 \\
\end{tabular} & 2793.9 & 259.6 & 49.4 & 1.55 & 0.31 \\
\hline
\end{tabular}

Table 1. Response optimization surface experimental design methodology for preparation of emulsions and adjusted variables to the model: $\zeta$, ADS, PDI, $\eta$ for fresh and stored emulsions at $20^{\circ} \mathrm{C}$ and $4{ }^{\circ} \mathrm{C}$, and hardness, cohesiveness and springiness of oleogels.

ness and springiness of the gels as proposed by Friedman and collaborators ${ }^{18}$. Only significant variables were reported. Assays were performed at room temperature with a TA.XT plus texture analyzer (Stable Micro Systems, Godalming, UK).

Ice cream formulation and analysis. Two different ice cream formulations were produced. The fat used in the first ice cream was milk cream (Parmalat Colombia Ltda, Bogotá, Colombia), and the second used the emulsion with the best conditions as determined by numerical optimization (lowest $\zeta$ and ADS). In an UltraTurrax (T-25 basic, IKA) at $8000 \mathrm{rpm}, 240 \mathrm{~mL}$ of whole milk, $174.6 \mathrm{~g}$ of sugar and $0.20 \mathrm{~g}$ of salt were homogenized; separately, the respective fat and vanilla essence were homogenized under the same procedure, after which all ingredients were mixed (Imusa, Bogotá, Colombia) and allowed to cool $\left(5^{\circ} \mathrm{C}\right)$ for $12 \mathrm{~h}$. The mixture was then added to an Ice Cream Maker Model ICE-21R (Cuisinart, New Jersey, USA) and stirred for 20 min to form ice creams. Once soft ice creams were formed, they were placed in a container and frozen at $-17^{\circ} \mathrm{C}$ for $48 \mathrm{~h}$. The ice creams were subjected to a texture profile analysis using a TA.XT plus texture analyzer (Stable Micro Systems, Godalming, UK) in order to determine hardness, cohesiveness, springiness, adhesiveness, chewiness and gumminess. Furthermore, the viscosity of the ice creams was measured using the same conditions described for the determination of viscosity of the oleogels.

\section{Results and discussion}

Effects of MF on the $\zeta$, ADS, PDI, $\eta$ of fresh emulsions. $\zeta$-potential of fresh emulsions. The influence of various factors on the $\zeta$ of fresh emulsions was determined. Values of $\zeta$ ranged from -16.4 to $-30.5 \mathrm{mV}$ (Table 1). The factors that significantly affected $\zeta$ were oil concentration (B), WP concentration (C), type of oil (D), temperature $(E)$, surfactant $(F)$, type of WP $(G)$, WP concentration squared $\left(C^{2}\right)$, and the interactions $A D$, AG, BE, BG, CD, CG, DE, DF, DG, EG and FG. These values were adjusted to a quadratic model with an $\mathrm{R}^{2}$ of $0.99(\mathrm{P}<0.05)$, and the lack of fit was not significant (Table 2). According to the results obtained, the presence of soy lecithin $(\mathrm{F})$ is significant considering the $\zeta$ value of fresh emulsions. This agrees with the results of Wang et al. ${ }^{19}$, who found that increasing the concentration of lecithin in an emulsion with whey protein isolate (WPI) and peony oil resulted in a $\zeta$ that was approximately $10 \%$ more negative than that of an emulsion without lecithin. This can be attributed to the fact that the conformational changes on WP induced by lecithin binding could promote the exposure of negatively charged WP residues and therefore decrease $\zeta$.

Another factor that affected the stability of emulsions was the oil concentration, as lower values of $\zeta$ were obtained at higher oil concentrations (Table 1). This behavior may occur because the oils used are composed of medium chain (VCO) and long chain triglycerides (HOPO and SO) with fatty acids of 10 to 18 carbon atoms in length and have low molecular weights ${ }^{20}$. Because VCO, HOPO and SO oils have proportions of monounsaturated (oleic) and polyunsaturated fatty acids (linoleic and linolenic), their structure (double bonds) makes them more sensitive to extrinsic factors such as increased temperature and pressure, which also catalyzes protein hydrolysis.

The interactions between the type of whey and all the factors evaluated in the experimental design were significant. This was verified experimentally, as in emulsions made with WP2 whey, although no separation of phases was observed during two weeks of evaluation, oleogels were never formed and these emulsions exhibited the highest values of $\zeta$, in contrast to WP1 and WP3 whey samples, which always formed oleogels. This may be because the steric repulsion between dispersed oil droplets is not high enough to overcome the intermolecular attraction force between the droplets and the energy barrier. As a result, the emulsion gels after a few days because the WPs tend to aggregate together with the oil droplets as the temperature increases during $\mathrm{MF}^{21}$.

ADS and PDI of fresh emulsions. The results obtained from ADS and PDI are shown in Table 1. A small ADS (nm scale) is of interest because droplet size is strongly correlated with high stability in conventional emulsion systems $^{22}$. The factors that were significant in the ADS were oil concentration (B), surfactant (F), type of WP (G) and pressure-type of WP (AG) and surfactant-type of WP (FG) interactions, and the values obtained were fitted to a quadratic model with an $\mathrm{R}^{2}$ of $0.97(P<0.05)$, in which the lack of fit was not significant (Table 2$)$. The results demonstrate that ADS, and the charge of oil droplets in emulsions can be controlled by selecting an appropriate emulsifier (type and concentration) and an appropriate homogenization procedure (MF, cycles, temperature ${ }^{23}$.

The ADS of the emulsions was significantly reduced by the pressure used in the microfluidizer (Fig. 1). The same results were obtained by Dissanayake et al. ${ }^{24}$, who concluded that MF directly reduces the particle size in emulsions made with WP powder. High shear homogenizers such as a Microfluidizer promote two processes: 


\begin{tabular}{|c|c|c|c|c|c|c|c|c|c|c|c|c|}
\hline \multirow[b]{2}{*}{ Independent factor } & \multicolumn{3}{|c|}{$\zeta$-Potential (mV) } & \multicolumn{3}{|c|}{ ADS (nm) } & \multicolumn{3}{|l|}{ PDI } & \multicolumn{3}{|c|}{$\eta_{\text {Fresh }}(\mathrm{mPa}$ s) } \\
\hline & SS & df & $P$-value & SS & df & $P$-value & SS & df & $p$-value & SS & df & $P$-value \\
\hline Model & 734.19 & 46 & $<0.0001$ & $9.9 \times 10^{5}$ & 46 & 0.002 & 0.749 & 46 & 0.0035 & $1.2 \times 10^{6}$ & 46 & $<0.0001$ \\
\hline A (Pressure) & 0.01 & 1 & 0.86 & $2.5 \times 10^{3}$ & 1 & 0.42 & 0.003 & 1 & 0.38 & $1.2 \times 10^{4}$ & 1 & 0.001 \\
\hline B (Oil \%) & 2.13 & 1 & 0.04 & $7.9 \times 10^{4}$ & 1 & 0.0008 & 0.084 & 1 & 0.0004 & $1.0 \times 10^{4}$ & 1 & 0.014 \\
\hline C (Whey \%) & 12.95 & 1 & 0.0001 & $3.5 \times 10^{4}$ & 1 & 0.01 & 0.021 & 1 & 0.026 & $3.2 \times 10^{5}$ & 1 & $<0.0001$ \\
\hline D (Type of oil) & 37.90 & 2 & $<0.0001$ & $2.6 \times 10^{4}$ & 2 & 0.06 & 0.038 & 2 & 0.02 & $2.8 \times 10^{2}$ & 2 & 0.8867 \\
\hline $\mathrm{E}($ Control To $)$ & 4.56 & 1 & 0.005 & $8.9 \times 10^{3}$ & 1 & 0.14 & 0.013 & 1 & 0.06 & $4.3 \times 10^{1}$ & 1 & 0.9849 \\
\hline F (Lecithin) & 5.07 & 1 & 0.004 & $3.7 \times 10^{4}$ & 1 & 0.009 & 0.026 & 1 & 0.015 & $6.5 \times 10^{4}$ & 1 & $<0.0001$ \\
\hline G (WP) & 411.80 & 2 & $<0.0001$ & $1.4 \times 10^{5}$ & 2 & 0.0004 & 0.084 & 2 & 0.0013 & $1.5 \times 10^{5}$ & 2 & $<0.0001$ \\
\hline $\mathrm{AB}$ & 0.28 & 1 & 0.40 & $8.0 \times 10^{3}$ & 1 & 0.16 & 0.009 & 1 & 0.12 & $1.7 \times 10^{4}$ & 1 & 0.0031 \\
\hline $\mathrm{AD}$ & 8.50 & 2 & 0.002 & $8.4 \times 10^{3}$ & 2 & 0.34 & 0.005 & 2 & 0.46 & $9.4 \times 10^{2}$ & 2 & 0.68 \\
\hline AG & 18.27 & 2 & 0.0001 & $6.8 \times 10^{4}$ & 2 & 0.005 & 0.019 & 2 & 0.09 & $2.1 \times 10^{3}$ & 2 & 0.43 \\
\hline $\mathrm{BC}$ & 0.05 & 1 & 0.72 & $3.0 \times 10^{2}$ & 1 & 0.78 & 0.016 & 1 & 0.04 & $5.1 \times 10^{3}$ & 1 & \begin{tabular}{|l|}
0.061 \\
\end{tabular} \\
\hline $\mathrm{BD}$ & 1.17 & 2 & 0.25 & $2.7 \times 10^{4}$ & 2 & 0.06 & 0.010 & 2 & 0.24 & $2.1 \times 10^{4}$ & 2 & 0.005 \\
\hline $\mathrm{BE}$ & 2.29 & 1 & 0.03 & $9.4 \times 10^{2}$ & 1 & 0.61 & 0.003 & 1 & 0.37 & $4.1 \times 10^{3}$ & 1 & 0.09 \\
\hline $\mathrm{BF}$ & 0.57 & 1 & 0.24 & $4.6 \times 10^{2}$ & 1 & 0.72 & 0.003 & 1 & 0.32 & $1.9 \times 10^{4}$ & 1 & 0.002 \\
\hline BG & 5.60 & 2 & 0.009 & $1.9 \times 10^{3}$ & 2 & 0.77 & 0.036 & 2 & 0.02 & $3.3 \times 10^{4}$ & 2 & 0.001 \\
\hline $\mathrm{CD}$ & 5.01 & 2 & 0.01 & $1.2 \times 10^{4}$ & 2 & 0.24 & 0.003 & 2 & 0.58 & $3.8 \times 10^{3}$ & 2 & 0.242 \\
\hline $\mathrm{CF}$ & 0.71 & 1 & 0.19 & $6.2 \times 10^{3}$ & 1 & 0.21 & 0.009 & 1 & 0.11 & $5.1 \times 10^{4}$ & 1 & $<0.0001$ \\
\hline CG & 41.03 & 2 & $<0.0001$ & $1.0 \times 10^{4}$ & 2 & 0.27 & 0.039 & 2 & 0.02 & $6.4 \times 10^{4}$ & 2 & $<0.0001$ \\
\hline $\mathrm{DE}$ & 12.77 & 2 & 0.0005 & $1.1 \times 10^{4}$ & 2 & 0.26 & 0.011 & 2 & 0.22 & $1.1 \times 10^{4}$ & 2 & 0.038 \\
\hline $\mathrm{DF}$ & 4.29 & 2 & 0.02 & $7.1 \times 10^{3}$ & 2 & 0.4 & 0.002 & 2 & 0.69 & $1.5 \times 10^{4}$ & 2 & \begin{tabular}{|l|}
0.02 \\
\end{tabular} \\
\hline DG & 12.74 & 4 & 0.003 & $3.6 \times 10^{4}$ & 4 & 0.10 & 0.018 & 4 & 0.29 & $1.5 \times 10^{4}$ & 4 & 0.06 \\
\hline EG & 5.32 & 2 & 0.01 & $2.4 \times 10^{4}$ & 2 & 0.075 & 0.001 & 1 & 0.67 & $2.6 \times 10^{4}$ & 2 & 0.003 \\
\hline FG & 31.07 & 2 & $<0.0001$ & $9.7 \times 10^{4}$ & 2 & 0.001 & 0.009 & 2 & 0.001 & $5.6 \times 10^{4}$ & 2 & 0.0001 \\
\hline $\mathrm{C}^{2}$ & 2.85 & 1 & 0.02 & $1.7 \times 10^{3}$ & 1 & 0.50 & 0.002 & 1 & 0.45 & $4.0 \times 10^{4}$ & 1 & 0.0002 \\
\hline Residual & 3.63 & 10 & - & $3.5 \times 10^{4}$ & 10 & - & 0.030 & 10 & - & $1.2 \times 10^{4}$ & 10 & - \\
\hline Lack of fit & 2.62 & 5 & 0.16 & $2.7 \times 10^{4}$ & 5 & 0.11 & 0.015 & 5 & 0.49 & $7.8 \times 10^{3}$ & 5 & 0.21 \\
\hline Pure Error & 1.00 & 5 & - & $8.1 \times 10^{3}$ & 5 & - & 0.015 & 5 & - & $3.7 \times 10^{3}$ & 5 & - \\
\hline $\mathrm{R}^{2}$ & 0.99 & - & - & 0.97 & - & - & 0.96 & - & - & 0.99 & - & - \\
\hline Adj $R^{2}$ & 0.97 & - & - & 0.80 & - & - & 0.78 & - & - & 0.94 & - & - \\
\hline
\end{tabular}

Table 2. ANOVA for the adjusted variables to response optimization design: $\zeta$, ADS, PDI, and $\eta$ for fresh emulsions. Values in bold represent $p$ values lower than 0.05 which have a significant effect

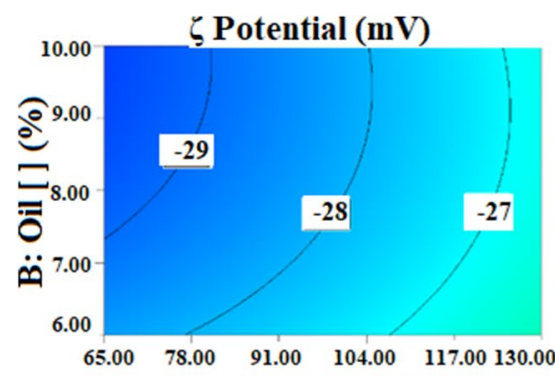

A: Pressure (MPa)

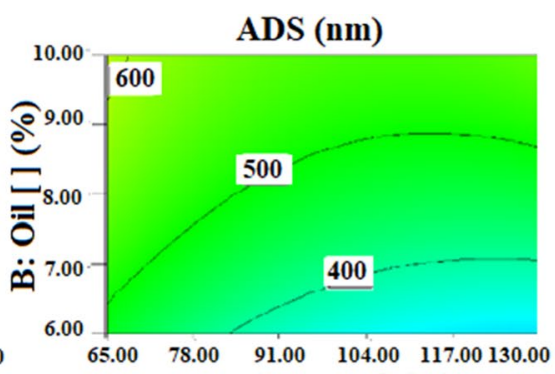

A: Pressure (MPa)

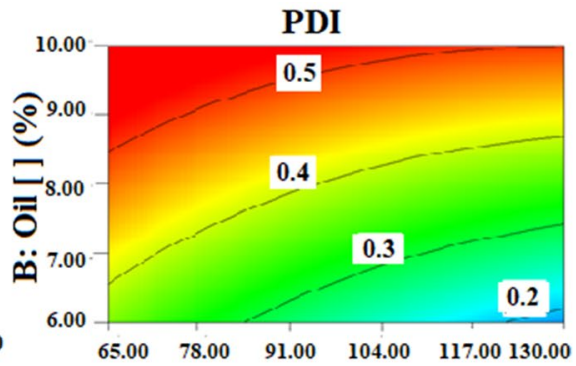

A: Pressure (MPa)

Figure 1. Graphs of the models of $\zeta$, ADS and PDI in function of pressure (x axis) and oil concentration (y axis).

droplet break-up and re-coalescence, which when combined are enough to decrease ADS, depending on the oil concentration, presence of surfactant and WP type. Similarly, fat globules are intimately connected to proteins, as highly interconnected and dense networks were formed in most emulsions ${ }^{25}$. On the other hand, in most emulsions made with WP2 whey, oleogels were not formed, probably due to the large particle size of these emulsions, which led to a lower capacity to form gels ${ }^{6}$.

PDI is a dimensionless parameter describing the relative width or variance of the particle size distribution ${ }^{17}$. The PDI can assume values lower than 0.05 for monodisperse distributions and values above 0.7 in samples with very large size distributions 9 . As seen in Table 1 , the PDI values varied between 0.12 and 0.52 , which indicate that the emulsions were polydisperse ${ }^{26}$. However, a relatively narrow droplet size distribution was observed, which 


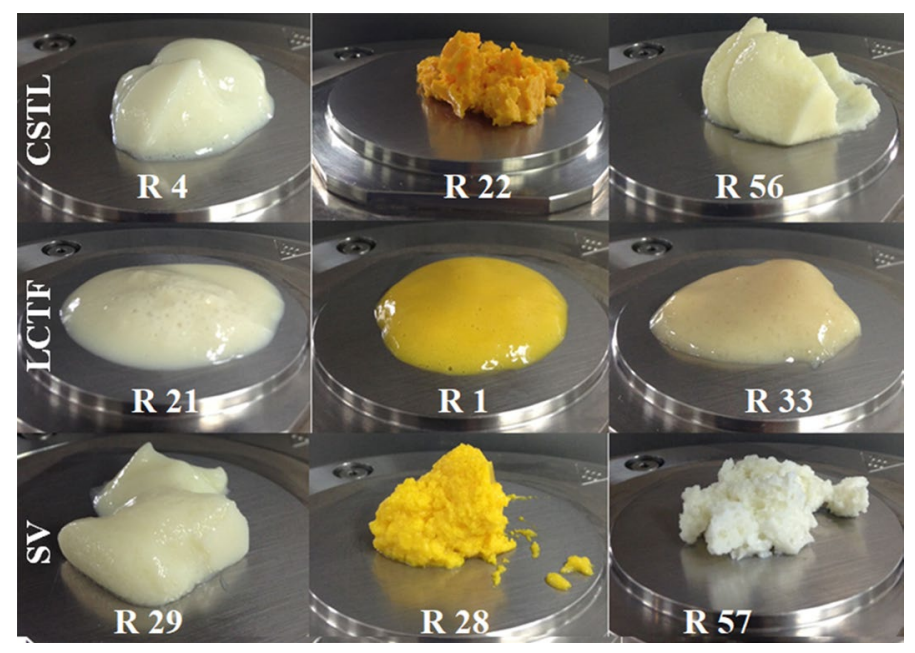

Figure 2. Oleogels formed with different WP and oils by MF. Rows: 1. WP1, 2. WP2 and 3.WP3, columns: 1. $\mathrm{SO}, 2$. HOPO, 3. VCO. R corresponds to the run (emulsion) of the experimental design.

suggests that the MF method used to obtain the emulsions was satisfactory ${ }^{9}$. The oil concentration (B), the WP concentration (C), the type of oil (D), the surfactant (F), and the type of WP (G) significantly affected the PDI values (Table 2). This is because the proteins present in the WP are emulsifiers, as they are amphiphilic (having hydrophobic and hydrophilic residues) and have active surfaces, enabling them to form strong and cohesive membranes around the droplets, thereby stabilizing them in emulsions ${ }^{26}$. The PDI values were adjusted to a quadratic model with an $\mathrm{R}^{2}$ of $0.96(P<0.05)$, and the lack of fit was not significant (Table 2). Moreover, the interactions BC, BG, CG and FG significantly influenced PDI values.

$\eta$ of fresh emulsions. The rheological behavior of dairy products is complex and depends on the temperature, concentration and physical state of the dispersed phase ${ }^{7}$. The $\eta$ behavior of proteins in emulsions is the result of several factors, including the size, shape and polydispersity of protein molecules and their aggregates, proteinsolvent interactions, hydrodynamic volume and the molecular flexibility of proteins in their hydrated state ${ }^{27}$. According to the results for fresh emulsions (Table 1), factors that significantly influenced the $\eta$ of the fresh emulsions were pressure (A), oil concentration (B), WP concentration (C), surfactant (F), type of WP (G), WP concentration squared $\left(\mathrm{C}^{2}\right)$ and the interactions $\mathrm{AB}, \mathrm{BD}, \mathrm{BF}, \mathrm{BG}, \mathrm{CF}, \mathrm{CG}, \mathrm{DE}, \mathrm{DF}, \mathrm{EG}$ and FG (Table 2). The values were adjusted to a quadratic model with an $\mathrm{R}^{2}$ of $0.99(P<0.05)$, and the lack of fit was not significant (Table 2). The concentration of WP was significant, as above the critical concentration, the distances between particles are smaller and colloidal interactions are stronger, which leads to additional associations of these aggregates and, eventually, a higher $\eta^{28}$.

Effects of MF on the $\eta$ of oleogels stored at different temperatures. Many food products can be classified as gelled emulsions or emulsion gels. This applies to protein-based oil-in-water emulsions, which can be converted into soft-solids by food processing operations such as heating, acidification, pressure, and enzymatic action. However, the denaturation and aggregation of globular proteins by high-pressure treatments, such as MF, provides an alternative to thermal treatment for the gelation of protein-based colloidal systems ${ }^{27}$.

Of the resulting emulsions, $63 \%$ were highly stable with no phase separation, as MF treatment resulted in more structured systems ${ }^{12}$. Likewise, MF generates more homogeneously sized particles, which prevented emulsions from separating ${ }^{3}$; even emulsions that gelled without further heat treatment were obtained (Fig. 2).

Similar to Zhu et al. ${ }^{29}$, emulsions that were stored at room temperature formed oleogels due to the flocculation of oil droplets, which led to the formation of a gel-type network (oleogel) in these emulsions. The oil concentration and its interaction with the other evaluated parameters were the main factors that most greatly influenced the viscosity variable (Table 3 ). As mentioned above, this can be attributed to the effect of temperature and pressure on the double bonds of the mono and polyunsaturated components of VCO, HOPO and SO oils.

The stability of emulsions stabilized with WP proteins ${ }^{30}$ depends on the ADS, PDI, type of oil and crystallization of the fats present. Also, when emulsions are cooled to temperatures where part of the fat phase becomes crystalline, fat crystals from one droplet may penetrate into another droplet leading to emulsion destabilization by partial coalescence ${ }^{31}$. During our experiments, we observed that some of the emulsions containing VCO had crystallized particles, and as found by McClements ${ }^{32}$, changes in the physicochemical properties (rheology and appearance) of these oleogels were observed. The changes in appearance observed were the formation of small crystals in the oleogels and changes in color, which may have been the result of Maillard reactions catalyzed by the denaturation of the WPs ${ }^{33}$, a side effect of MF.

Changes in the $\eta$ when emulsions were stored at different temperatures (Table 1) could occur due to the shape and size of the crystals present, as, according to the results from emulsions stored at room temperature $\left(20^{\circ} \mathrm{C}\right)$, the factors that significantly influenced the $\eta$ were type of oil (D), type of WP $(G)$, oil concentration squared 


\begin{tabular}{|c|c|c|c|c|c|c|c|c|c|c|c|c|c|c|c|}
\hline \multirow{2}{*}{$\begin{array}{l}\text { Independent } \\
\text { factor }\end{array}$} & \multicolumn{3}{|c|}{$\eta_{\text {stored } 20^{\circ} \mathrm{C}}$ (mPa s) } & \multicolumn{3}{|c|}{$\eta_{\text {stored } 4^{\circ} \mathrm{C}}(\mathrm{mPa} \mathrm{s})$} & \multicolumn{3}{|c|}{ Hardness (N) } & \multicolumn{3}{|c|}{ Cohesiveness } & \multicolumn{3}{|c|}{ Springiness } \\
\hline & SS & df & $p$-value & SS & df & $p$-value & SS & df & $p$-value & SS & df & $p$-value & SS & df & $p$-value \\
\hline Model & $7.5 \times 10^{7}$ & 46 & 0.0015 & $1.8 \times 10^{7}$ & 46 & 0.045 & $2.0 \times 10^{5}$ & 46 & 0.006 & 1.95 & 46 & 0.023 & 2.937 & 46 & 0.003 \\
\hline A & $8.7 \times 10^{4}$ & 1 & 0.57 & $1.3 \times 10^{5}$ & 1 & 0.37 & $1.4 \times 10^{4}$ & 1 & 0.003 & 0.009 & 1 & 0.42 & 0.012 & 1 & 0.33 \\
\hline B & $7.2 \times 10^{5}$ & 1 & 0.12 & $1.7 \times 10^{4}$ & 1 & 0.74 & $9.3 \times 10^{2}$ & 1 & 0.33 & 0.09 & 1 & 0.024 & 0.111 & 1 & 0.012 \\
\hline $\mathrm{C}$ & $1.1 \times 10^{5}$ & 1 & 0.52 & $3.5 \times 10^{6}$ & 1 & 0.0006 & $4.5 \times 10^{4}$ & 1 & $<0.0001$ & 0.03 & 1 & 0.19 & 0.307 & 1 & 0.0005 \\
\hline $\mathrm{D}$ & $4.2 \times 10^{6}$ & 2 & 0.007 & $7.1 \times 10^{4}$ & 2 & 0.79 & $2.7 \times 10^{3}$ & 2 & 0.27 & 0.10 & 2 & 0.05 & 0.101 & 2 & 0.045 \\
\hline $\mathrm{F}$ & $6.1 \times 10^{5}$ & 1 & 0.15 & $4.0 \times 10^{5}$ & 1 & 0.13 & $2.0 \times 10^{4}$ & 1 & 0.0008 & 0.05 & 1 & 0.07 & 0.455 & 1 & $<0.0001$ \\
\hline G & $1.1 \times 10^{7}$ & 2 & 0.0002 & $2.2 \times 10^{6}$ & 2 & 0.0099 & $3.9 \times 10^{4}$ & 2 & 0.0002 & 0.13 & 2 & \begin{tabular}{|l|}
0.03 \\
\end{tabular} & 0.715 & 2 & $<0.0001$ \\
\hline $\mathrm{AC}$ & $3.0 \times 10^{6}$ & 1 & 0.006 & $2.4 \times 10^{4}$ & 1 & 0.69 & 1.9 & 1 & 0.97 & 0.06 & 1 & 0.0516 & 0.002 & 1 & 0.73 \\
\hline $\mathrm{BC}$ & $5.0 \times 10^{6}$ & 1 & 0.001 & $5.1 \times 10^{3}$ & 1 & 0.86 & $2.2 \times 10^{3}$ & 1 & 0.15 & 0.007 & 1 & 0.4709 & 0.009 & 1 & 0.40 \\
\hline $\mathrm{BD}$ & $4.2 \times 10^{6}$ & 2 & 0.007 & $9.6 \times 10^{5}$ & 2 & 0.08 & $5.5 \times 10^{3}$ & 2 & 0.09 & 0.19 & 2 & 0.0101 & 0.067 & 2 & 0.10 \\
\hline $\mathrm{BF}$ & $2.8 \times 10^{6}$ & 1 & 0.007 & $3.9 \times 10^{5}$ & 1 & 0.14 & $1.0 \times 10^{3}$ & 1 & 0.31 & 0.01 & 1 & 0.3811 & 0.002 & 1 & 0.68 \\
\hline BG & $2.3 \times 10^{5}$ & 2 & \begin{tabular}{|l|}
0.64 \\
\end{tabular} & $4.2 \times 10^{5}$ & 2 & 0.29 & $4.8 \times 10^{3}$ & 2 & 0.12 & 0.20 & 2 & 0.0092 & 0.011 & 2 & 0.64 \\
\hline $\mathrm{CD}$ & $3.5 \times 10^{6}$ & 2 & 0.012 & $5.8 \times 10^{5}$ & 2 & 0.19 & $5.7 \times 10^{2}$ & 2 & 0.73 & 0.05 & 2 & 0.1846 & 0.003 & 2 & \begin{tabular}{|l|}
0.88 \\
\end{tabular} \\
\hline $\mathrm{CF}$ & $2.5 \times 10^{6}$ & 1 & 0.010 & $1.0 \times 10^{6}$ & 1 & 0.02 & $4.8 \times 10^{2}$ & 1 & 0.48 & 0.29 & 1 & 0.0007 & 0.020 & 1 & 0.22 \\
\hline CG & $2.4 \times 10^{5}$ & 2 & 0.63 & $8.8 \times 10^{4}$ & 2 & 0.75 & $2.3 \times 10^{4}$ & 2 & 0.002 & 0.02 & 2 & 0.5316 & 0.081 & 2 & 0.07 \\
\hline $\mathrm{DF}$ & $2.2 \times 10^{6}$ & 2 & 0.042 & $4.4 \times 10^{5}$ & 2 & 0.27 & $7.5 \times 10^{2}$ & 2 & 0.67 & 0.002 & 2 & 0.9265 & 0.056 & 2 & 0.14 \\
\hline DG & $5.5 \times 10^{6}$ & 4 & 0.013 & $9.9 \times 10^{5}$ & 4 & 0.23 & $4.5 \times 10^{3}$ & 4 & 0.36 & 0.21 & 4 & 0.0311 & 0.100 & 4 & 0.15 \\
\hline EG & $2.0 \times 10^{6}$ & 2 & 0.05 & $4.2 \times 10^{5}$ & 2 & 0.29 & $7.9 \times 10^{3}$ & 2 & 0.04 & 0.0001 & 2 & 0.9942 & 0.020 & 2 & 0.46 \\
\hline FG & $2.7 \times 10^{6}$ & 2 & 0.03 & $5.2 \times 10^{5}$ & 2 & 0.22 & $2.9 \times 10^{3}$ & 2 & 0.25 & 0.01 & 2 & 0.5807 & 0.034 & 2 & 0.28 \\
\hline $\mathrm{B}^{2}$ & $2.4 \times 10^{6}$ & 1 & 0.01 & $6.5 \times 10^{3}$ & 1 & 0.83 & $6.5 \times 10^{3}$ & 1 & 0.02 & 0.02 & 1 & 0.1940 & 0.055 & 1 & 0.06 \\
\hline $\mathrm{C}^{2}$ & $8.5 \times 10^{6}$ & 1 & 0.0002 & $1.2 \times 10^{6}$ & 1 & 0.02 & $9.7 \times 10^{2}$ & 1 & 0.32 & 0.11 & 1 & 0.0149 & 0.053 & 1 & 0.06 \\
\hline Residual & $2.5 \times 10^{6}$ & 10 & - & $1.5 \times 10^{6}$ & 10 & - & $9.0 \times 10^{3}$ & 10 & - & 0.13 & 10 & - & 0.118 & 10 & - \\
\hline Lack of fit & $2.3 \times 10^{6}$ & 5 & 0.007 & $1.4 \times 10^{6}$ & 5 & 0.007 & $8.0 \times 10^{3}$ & 5 & 0.019 & 0.11 & 5 & 0.05 & 0.095 & 5 & 0.07 \\
\hline Pure Error & $1.8 \times 10^{5}$ & 5 & - & $1.0 \times 10^{5}$ & 5 & - & $9.9 \times 10^{2}$ & 5 & - & 0.02 & 5 & - & 0.023 & 5 & - \\
\hline $\mathrm{R}^{2}$ & 0.97 & - & - & 0.93 & - & - & 0.96 & - & - & 0.94 & - & - & 0.96 & - & - \\
\hline Adj $R^{2}$ & 0.82 & - & - & 0.58 & - & - & 0.76 & - & - & 0.66 & - & - & 0.78 & - & - \\
\hline
\end{tabular}

Table 3. ANOVA for the adjusted variables to response optimization design $\eta$ for stored emulsions at $20^{\circ} \mathrm{C}$ and $4{ }^{\circ} \mathrm{C}$, and hardness, cohesiveness and springiness of oleogels. Values in bold represent $p$ values lower than 0.05 which have a significant effect

$\left(\mathrm{B}^{2}\right)$, WP concentration squared $\left(\mathrm{C}^{2}\right)$ and the interactions between $\mathrm{AC}, \mathrm{BC}, \mathrm{BD}, \mathrm{BF}, \mathrm{CD}, \mathrm{CF}, \mathrm{DF}, \mathrm{DG}$ and FG (Table 3). Significant factors affecting the $\eta$ of emulsions stored at $4{ }^{\circ} \mathrm{C}$ were WP concentration (C), type of WP $(\mathrm{G})$, WP concentration squared $\left(\mathrm{C}^{2}\right)$ and the interactions between $\mathrm{CF}$. The values obtained were adjusted to a quadratic model with $\mathrm{R}^{2}$ values of 0.96 and $0.92(P<0.05)$, respectively. As MF is a high pressure process, it causes temperature increases, producing the thermal denaturation of $\beta$ - $\mathrm{Lg}$, which is characterized by the alteration of secondary and tertiary structures, thereby exposing hydrophobic residues to solvent, which leads to the aggregation and intermolecular bonding of the matrix components ${ }^{34}$ and could be observed in the formation of oleogels in the majority of emulsions.

Most of the emulsions stored at $4{ }^{\circ} \mathrm{C}$ had lower values of $\eta$ than emulsions that were stored at room temperature (Table 1), possibly because in low temperature emulsions the speed and frequency of collisions between droplets are lower, which reduces the growth of droplet size in the emulsion ${ }^{9,35}$ and the aggregation rate of WPs. When used as emulsions, WP aggregates influence various factors, including surface hydrophobicity, protein flexibility, electrostatic interactions, steric effects, ionic strength and protein concentration ${ }^{36}$. For all of the above reasons, MF greatly improves the efficiency of emulsification and gelling through a combined mechanism of cavitation, shear and impact and therefore has great potential for the preparation of oleogels ${ }^{12}$.

Effects of heat treatment on different texture parameters of emulsions. The effect of the heat treatment $\left(90^{\circ} \mathrm{C}\right)$ of emulsions on texture parameters such as hardness, cohesiveness and springiness was evaluated (Table 1). The factors that significantly influenced hardness were pressure (A), WP concentration (C), surfactant $(F)$, type of WP $(G)$, oil concentration squared $\left(B^{2}\right)$ and $C G$ and EG interactions (Table 3), which define the intensity of the forces present in the gel (hydrophobic, hydrophilic and covalent bonds) and compromise the structure of proteins in the $\mathrm{WP}^{37}$. The hardness values were adjusted to a quadratic model with a $\mathrm{R}^{2}$ of $0.96(P<$ $0.05)$, and the lack of fit was significant. The experimental results agree with the results obtained by Devi et al..$^{38}$, who concluded that the factors that affect hardness in gels made with WP are the composition of WP, pressure, concentration of WP, time of pressure treatment, temperature and $\mathrm{pH}$.

The factors that significantly affected cohesiveness were oil concentration (B), type of WP (G), WP concentration squared $\left(\mathrm{C}^{2}\right)$ and the interactions of $\mathrm{AB}, \mathrm{BD}, \mathrm{BG}$ and $\mathrm{CF}$ (Table 3 ). These factors were decisive and responsible for promoting intermolecular polymerization through the formation and increase of cohesiveness 


\begin{tabular}{|l|l|l|c|c|c|l|}
\hline Ice cream & Hardness $(\mathbf{N})$ & Cohesiveness & Springiness & Adhesiveness $(\mathbf{N} \times \mathbf{m m})$ & Chewiness $(\mathbf{N})$ & Gumminess $(\mathbf{N})$ \\
\hline Traditional & $1010.74^{\mathrm{a}}(344.0)$ & $3.865^{\mathrm{a}}(0.6)$ & $0.456^{\mathrm{a}}(0.2)$ & $-157.225^{\mathrm{a}}(28.8)$ & $1497.7^{\mathrm{a}}(847.7)$ & $3539.75^{\mathrm{a}}(931.2)$ \\
\hline Optimized & $1277.95^{\mathrm{a}}(578.9)$ & $6.515^{\mathrm{b}}(0.9)$ & $0.6925^{\mathrm{a}}(0.3)$ & $-73.54^{\mathrm{b}}(13.3)$ & $3381.83^{\mathrm{b}}(939.8)$ & $6121.73^{\mathrm{b}}(1691.3)$ \\
\hline
\end{tabular}

Table 4. Texture profile analysis TPA of the two ice cream formulated with milk cream (traditional) and with

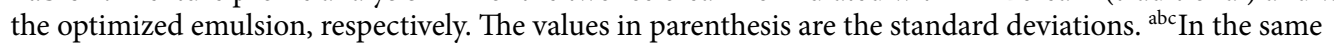
column, means without the same letter reveal significant differences $(p<0.05)$ according to the LSD multiple range test.

within gels ${ }^{39}$. The experimental values were adjusted to a quadratic model with an $\mathrm{R}^{2}$ of $0.94(P<0.05)$, and the lack of fit was not significant.

The significant factors affecting springiness were similar to those for hardness: oil concentration (B), WP concentration (C), type of oil (D), surfactant (F), G (type of WP) and AG interaction (Table 3). This may be because the gels made with denatured WP had greater resistance due to the presence of intermolecular di-sulfide bonds, which are believed to confer springiness to WP gels ${ }^{40}$. This result can also be attributed to a physical phenomenon resulting from the increased chain length of the protein aggregates after heat treatment, which restricts mobility by cross-linking and therefore increases non-covalent interactions $\mathrm{s}^{40}$. The obtained values were adjusted to a quadratic model with an $\mathrm{R}^{2}$ of $0.94(P<0.05)$, and the lack of fit was not significant.

Oleogel optimization and further elaboration of ice cream. After experiments were performed and to obtain an emulsion with the lowest $\zeta$ and ADS for use as an ice cream base, numerical and graphical optimization of the Design Expert software was used for response optimization following the desirability and criterion ${ }^{41}$. Numerical optimization yielded 100 different solutions (data not shown) with a desirability between 0.953 and 1. Solution 65 was chosen, which had the following parameters: pressure $120.97 \mathrm{MPa}$; oil concentration $6.80 \%$; concentration of WP 46.03\%; oil type HOPO; no temperature control during MF; surfactant and WP1; a desirability of $0.99^{\prime}$ and prediction $\zeta$ and ADS values of $-30.19 \mathrm{mV}$ and $172.25 \mathrm{~nm}$, respectively. The experimental errors for $\zeta$ and ADS were $3.2 \%$ and $0.6 \%$, respectively. This solution was chosen due to the ratio oil:WP and the lack of control temperature needed during the MF that simplifies the process allowing the production of an oleogel that exhibits the desired characteristics.

High oleic palm oil (HOPO) is a hybrid between Elaeis oleifera and Elaeis guineensis, and its oleic acid content is significantly different from African palm oil (54.6 \pm 1.0 vs. $41.4 \pm 0.3)^{40}$. HOPO is more unsaturated and has nutritional and technical advantages ${ }^{42}$. African palm oil, mainly extracted from E. guineensis, has been a source of criticism in recent years, as it is a rich source of saturated fatty acids (SFA), specifically palmitic acid, and its use in food products has been somewhat discouraged. The results of Mozzon et al. ${ }^{43}$, demonstrate that the partial dietary replacement of saturated palmitic acid with monounsaturated oleic acid can be achieved by consuming HOPO instead of African palm oil, without the need for any fractionation processes to separate olein and stearin fractions. On the other hand, presence of these type of oil in oleogels can change the functional properties of proteins, which introduces the possibility of improving the rheological and sensory properties (texture) of food products such as ice cream $^{34}$.

Rheological information helps to predict the mouthfeel, storage stability and durability, also to verify consistency, perform quality control and accelerate product development, for example, in dairy products. All of these attributes can be complemented with a TPA, which aims to simulate the repeated biting or chewing of a food in the mouth ${ }^{44}$ and provides parameters of hardness, springiness, adhesiveness, cohesiveness, chewiness and gumminess. Thus, as HOPO has excellent nutritional properties, it was used for the development of an ice cream prototype, besides being the oil, in which according to the optimization, it produced the emulsion with the lowest $\zeta$ and ADS. To determine whether the best emulsion resulting from optimization could replace the fat (cream) used in ice cream preparation, two different ice creams were made, one with milk cream (traditional ice cream) and one with the optimized emulsion. These ice creams were characterized according to their textural and rheological properties.

Ice cream's resistance to the mechanical forces imparted by the tongue, the upper palate and the teeth, and the general perception of the texture of ice cream are part of its sensory acceptance. TPA can quantify the factors that are part of this acceptance ${ }^{45}$. The results obtained from TPA for the two ice creams (traditional and optimized) studied, were analyzed by ANOVA (Table 4). Trasditional ice cream presented lower cohesiveness, chewiness and gumminess and higher adhesiveness compared to optimized ice cream $(\mathrm{P}<0.05)$. On the other hand, no significant differences $(\mathrm{P}>0.05)$ were obtained between hardness and springiness of the two ice creams studied. Results suggests that the oleogels obtained from the microfluidization of whey and HOPO are a viable option for the replacement of raw materials (cream) in the production of ice cream, with added value provided by WP and HOPO.

The viscosity of ice cream is an important parameter for determining the behavior of the fluid. Many factors contribute to ice cream viscosity, such as the interaction of hydrocolloids present in water, and other solutes (minerals) ${ }^{45}$. The flow curve of the ice cream made with HOPO was higher than that of the ice cream made without HOPO, which may be because the presence of pressurized and therefore denatured WP produced a more viscous ice cream. The apparent viscosity decreased as the shear rate increased, such that the ice creams displayed a pseudoplastic behavior. 


\section{Conclusions}

Through surface response methodology, this study verified the production of stable emulsions from whey without the need to work with isolated proteins (WPI), containing $4 \%$ of whey and $6.8 \%$ of oil concentration. However, the physicochemical composition of these whey can produce significant $(\mathrm{P}<0.05)$ differences in variables such as ADS, PDI, $\zeta, k, \eta$ and texture parameters, according to the results obtained. It is important to use standardization processes in the dairy industry to properly use WP residues and assess the costs and benefits of their use. Although previous studies have investigated the formation of oleogels through different methodologies (e.g., heat treatment, solvent exchange), in this investigation microfluidization was used because it is a high-pressure treatment that forms structured systems (more stable WP emulsions) and, thanks to the decreased ADS of WP aggregates, oleogels were formed without additional heat treatment. Because these gels are food-grade quality, they can be used in the food, cosmetic or pharmaceutical industries, generating added value by using a byproduct at low production costs. Finally, the concentration and type of oil used are significant factors in the manufacture of oleogels, as establishing the maximum amount of hydrophobic components in an emulsion will prevent the formation of crystals. It is possible to make an ice cream using an oleogel as a cream substitute without significant differences in viscosity and texture properties such as hardness and springiness. Therefore, oleogels are a promising fat substitute for ice cream production.

Received: 13 July 2020; Accepted: 30 November 2020

Published online: 30 March 2021

\section{References}

1. Munk, M. B., Munk, D. M. E., Gustavsson, F. \& Risbo, J. Using ethylcellulose to structure oil droplets in ice cream made with high oleic sunflower oil. J. Food Sci. 83(10), 2520-2526 (2018).

2. Limpimwong, W., Kumrungsee, T., Kato, N., Yanaka, N. \& Thongngam, M. Rice bran wax oleogel: A potential margarine replacement and its digestibility effect in rats fed a high-fat diet. J. Funct. Foods 39, 250-256 (2017).

3. Iordache, M. \& Jelen, P. High pressure microfluidization treatment of heat denatured whey proteins for improved functionality. Innov. Food Sci. Emerg. 4(4), 367-376 (2003).

4. Zulim-Botega, D. C., Marangoni, A. G., Smith, A. K. \& Goff, H. D. Development of formulations and processes to incorporate wax oleogels in ice cream. J Food Sci. 78(12), C1845-C1851 (2013).

5. Patel, A. R., Cludts, N., Sintang, M. D. B., Lesaffer, A. \& Dewettinck, K. Edible oleogels based on water soluble food polymers: Preparation, characterization and potential application. Food Funct. 5(11), 2833-2841 (2014).

6. De Vries, A., Wesseling, A., Van der Linden, E. \& Scholten, E. Protein oleogels from heat-set whey protein aggregates. J. Colloid Interface Sci. 486, 75-83 (2017).

7. Sajedi, M., Nasirpour, A., Keramat, J. \& Desobry, S. Effect of modified whey protein concentrate on physical properties and stability of whipped cream. Food Hydrocolloid 36, 93-101 (2014).

8. Vaclavik, V. A. \& Christian, E. W. Proteins in food: An introduction. In Essentials of Food Science Food Science Text Series 3rd edn (eds Christian, E. W. \& Vaclavik, V. A.) 156 (Springer, New York, 2008).

9. Ricaurte, L., Perea-Flores, M. D. J., Martinez, A. \& Quintanilla-Carvajal, M. X. Production of high-oleic palm oil nanoemulsions by high-shear homogenization (microfluidization). Innov. Food Sci. Emerg. 35, 75-85 (2016).

10. Ricaurte, L., Hernández-Carrión, M., Moyano-Molano, M., Clavijo-Romero, A. \& Quintanilla-Carvajal, M. X. Physical, thermal and thermodynamical study of high oleic palm oil nanoemulsions. Food Chem. 256, 62-70 (2018).

11. Oboroceanu, D. et al. The effect of high pressure microfluidization on the structure and length distribution of whey protein fibrils. Int. Dairy J. 21(10), 823-830 (2011).

12. Tang, C.-H. \& Liu, F. Cold, gel-like soy protein emulsions by microfluidization: Emulsion characteristics, rheological and microstructural properties, and gelling mechanism. Food Hydrocolloid 30(1), 61-72 (2013).

13. O'Sullivan, C. M., Barbut, S. \& Marangoni, A. G. Edible oleogels for the oral delivery of lipid soluble molecules: Composition and structural design considerations. Trends Food Sci. Technol. 57, 59-73 (2016).

14. De Vries, A., Hendriks, J., Van der Linden, E. \& Scholten, E. Protein oleogels from protein hydrogels via a stepwise solvent exchange route. Langmuir 31(51), 13850-13859 (2015)

15. Park, C. W., Bastian, E., Farkas, B. \& Drake, M. The effect of feed solids concentration and inlet temperature on the flavor of spray dried whey protein concentrate. J. Food Sci. 79(1), C19-C24 (2014).

16. Qian, C., Decker, E. A., Xiao, H. \& McClements, D. J. Physical and chemical stability of $\beta$-carotene-enriched nanoemulsions: Influence of $\mathrm{pH}$, ionic strength, temperature, and emulsifier type. Food Chem. 132(3), 1221-1229 (2012).

17. Rodrigues, R. M. et al. Influence of moderate electric fields on gelation of whey protein isolate. Food Hydrocolloid 43, 329-339 (2015).

18. Friedman, H. H., Whitney, J. E. \& Szczesniak, A. S. The texturometer-A new instrument for objective texture measurement. J. Food Sci. 28(4), 390-396 (1963).

19. Wang, S. et al. Influence of soy lecithin concentration on the physical properties of whey protein isolate-stabilized emulsion and microcapsule formation. J. Food Eng. 207, 73-80 (2017).

20. Kinsella, R., Maher, T. \& Clegg, M. E. Coconut oil has less satiating properties than medium chain triglyceride oil. Physiol. Behav. 179, 422-426 (2017).

21. Ng, S.-K. et al. Development of a palm olein oil-in-water $(\mathrm{o} / \mathrm{w})$ emulsion stabilized by a whey protein isolate nanofibrils-alginate complex. LWT Food Sci. Technol. 82, 311-317 (2017).

22. Tavernier, I., Wijaya, W., Van der Meeren, P., Dewettinck, K. \& Patel, A. R. Food-grade particles for emulsion stabilization. Trends Food Sci. Technol. 50, 159-174 (2016).

23. McClements, D. J. \& Li, Y. Structured emulsion-based delivery systems: Controlling the digestion and release of lipophilic food components. Adv. Colloid Interface Sci. 159(2), 213-228 (2010).

24. Dissanayake, M., Liyanaarachchi, S. \& Vasiljevic, T. Functional properties of whey proteins microparticulated at low pH. J. Dairy Sci. 95(4), 1667-1679 (2012).

25. Ciron, C. I. E., Gee, V. L., Kelly, A. L. \& Auty, M. A. E. Comparison of the effects of high-pressure microfluidization and conventional homogenization of milk on particle size, water retention and texture of non-fat and low-fat yoghurts. Int. Dairy J. 20(5), 314-320 (2010).

26. Adjonu, R., Doran, G., Torley, P. \& Agboola, S. Formation of whey protein isolate hydrolysate stabilised nanoemulsion. Food Hydrocolloid 41, 169-177 (2014).

27. Dissanayake, M. Modulation of Functional Properties of Whey Proteins by Microparticulation. PhD thesis, School of Biomedical and Health Sciences, Victoria University (2011). 
28. Mudgal, P., Daubert, C. R. \& Foegeding, E. A. Kinetic study of $\beta$-lactoglobulin thermal aggregation at low pH. J. Food Eng. 106(2), 159-165 (2011).

29. Zhu, X.-F., Zhang, N., Lin, W.-F. \& Tang, C.-H. Freeze-thaw stability of pickering emulsions stabilized by soy and whey protein particles. Food Hydrocolloid 69, 173-184 (2017).

30. Thaiphanit, S., Schleining, G. \& Anprung, P. Effects of coconut (Cocos nucifera L.) protein hydrolysates obtained from enzymatic hydrolysis on the stability and rheological properties of oil-in-water emulsions. Food Hydrocolloids 60, 252-264 (2016).

31. Tangsuphoom, N. \& Coupland, J. N. Effect of surface-active stabilizers on the surface properties of coconut milk emulsions. Food Hydrocolloid 23(7), 1801-1809 (2009).

32. McClements, D. J. Crystals and crystallization in oil-in-water emulsions: Implications for emulsion-based delivery systems. Adv. Colloid Int. Sci. 174, 1-30 (2012).

33. Tham, T. W., Yeoh, A. T. \& Zhou, W. Characterisation of aged infant formulas and physicochemical changes. Food Chem. 219, $117-125$ (2017).

34. Gauche, C., Barreto, P. L. M. \& Bordignon-Luiz, M. T. Effect of thermal treatment on whey protein polymerization by transglutaminase: Implications for functionality in processed dairy foods. LWT Food Sci. Technol. 43(2), 214-219 (2010).

35. Adjonu, R., Doran, G., Torley, P. \& Agboola, S. Whey protein peptides as components of nanoemulsions: A review of emulsifying and biological functionalities. J. Food Eng. 122, 15-27 (2014).

36. Fachin, L. \& Viotto, W. H. Effect of $\mathrm{pH}$ and heat treatment of cheese whey on solubility and emulsifying properties of whey protein concentrate produced by ultrafiltration. Int. Dairy J. 15(4), 325-332 (2005).

37. Filomena-Ambrosio, A. et al. Changes of the water-holding capacity and microstructure of panga and tilapia surimi gels using different stabilizers and processing methods. Food Sci. Technol. Int. 22(1), 68-78 (2016).

38. Devi, A. F., Buckow, R., Hemar, Y. \& Kasapis, S. Structuring dairy systems through high pressure processing. J. Food Eng. 114(1), 106-122 (2013).

39. Doherty, S. B. et al. Development and characterisation of whey protein micro-beads as potential matrices for probiotic protection. Food Hydrocolloid 25(6), 1604-1617 (2011).

40. Otte, J., Schumacher, E., Ipsen, R., Ju, Z. \& Qvist, K. B. Protease-induced gelation of unheated and heated whey proteins: Effects of $\mathrm{pH}$, temperature, and concentrations of protein, enzyme and salts. Int. Dairy J. 9(11), 801-812 (1999).

41. Ricaurte, L., Correa, R. E. P., Perea-Flores, M. D. J. \& Quintanilla-Carvajal, M. X. Influence of milk whey on high-oleic palm oil nanoemulsions: Powder production, physical and release properties. Food Biophys. 12(4), 439-450 (2017).

42. Zapata, M. L. E. Situación y perspectivas del aceite de palma alto oleico OxG en Colombia. Rev. Palmas 31, 349-353 (2010).

43. Mozzon, M., Pacetti, D., Lucci, P., Balzano, M. \& Frega, N. G. Crude palm oil from interspecific hybrid Elaeis oleifera $\times$ Elaeis guineensis: Fatty acid regiodistribution and molecular species of glycerides. Food Chem. 141(1), 245-252 (2013).

44. Pereira, A. G. T. et al. Effects of the addition of mechanically deboned poultry meat and collagen fibers on quality characteristics of frankfurter-type sausages. Meat Sci. 89(4), 519-525 (2011).

45. Lim, S. Y., Swanson, B. G., Ross, C. F. \& Clark, S. High hydrostatic pressure modification of whey protein concentrate for improved body and texture of lowfat ice cream. J. Dairy Sci. 91(4), 1308-1316 (2008).

\section{Acknowledgements}

The authors wish to acknowledge to the Universidad de La Sabana for its help in this investigation through the funding of the ING-186-2016 project. Moreover, the authors thank to Cenipalma (Colombia) for kindly supplying the High Oleic Palm Oil used in this study and to Alexandra Mondragón Serna, Leader of the project of Health and Nutrition of Cenipalma.

\section{Author contributions}

E.S.-A. and M.X.Q.-C. was involved in the development of experimental work in the laboratory, calculations, and in the manuscript writing, correcting and editing. E.S.-A., M.X.Q.-C. and R.E.P.-C. were involved in the manuscript writing. M.X.Q.-C. conceived the project and the study hypothesis and was involved in the manuscript correcting. All authors read and approved the final manuscript. K.B.-E. was involved in the reviewing and editing of the article for its publication.

\section{Competing interests}

The authors declare no competing interests.

\section{Additional information}

Correspondence and requests for materials should be addressed to M.X.Q.-C.

Reprints and permissions information is available at www.nature.com/reprints.

Publisher's note Springer Nature remains neutral with regard to jurisdictional claims in published maps and institutional affiliations.

Open Access This article is licensed under a Creative Commons Attribution 4.0 International License, which permits use, sharing, adaptation, distribution and reproduction in any medium or format, as long as you give appropriate credit to the original author(s) and the source, provide a link to the Creative Commons licence, and indicate if changes were made. The images or other third party material in this article are included in the article's Creative Commons licence, unless indicated otherwise in a credit line to the material. If material is not included in the article's Creative Commons licence and your intended use is not permitted by statutory regulation or exceeds the permitted use, you will need to obtain permission directly from the copyright holder. To view a copy of this licence, visit http://creativecommons.org/licenses/by/4.0/.

(C) The Author(s) 2021 